\title{
Editorial \\ Cambios sociales: escenario para las enfermeras comunitarias
}

José Ramón Martínez Riera'

1. Profesor titular de la Facultad de Ciencias de la Salud, Universidad de Alicante, España. Presidente de la Asociación Española de Enfermería Comunitaria (AEC). Secretario general de la Asociación Latinoamericana de Escuelas y Facultades de Enfermería (Aladefe). 
Nos encontramos ante una sociedad en permanente evolución y con constantes cambios en su forma de estructurarse, relacionarse y comunicarse. Esto, que puede considerarse normal, e incluso necesario, conduce no solo a la adaptación de las personas que configuran dicha sociedad, sino a la profunda modificación de las necesidades y las demandas de salud.

Por su parte, las organizaciones de salud y sus profesionales se ven abocados a redimensionar sus competencias, a fin de adaptarse tanto a los cambios como a las nuevas exigencias de personas, familias y comunidad. Así mismo, la Universidad no es ajena a los cambios sociales y, como parte de la sociedad que es, ha tenido que movilizarse y trabajar activamente en adaptaciones curriculares y en los planteamientos de sus investigaciones. El problema está, como tantas otras veces, en lograr una adecuada coordinación, vertebración y sintonía entre la teoría y la práctica, entre la sociedad y la universidad, como si fueran entes independientes que no precisan la una de la otra.

La sociedad, en su conjunto, debe ser consciente de la importancia que la universidad tiene como un recurso fundamental de su estructura vital. La universidad, por su parte, debe dejar de vivir a espaldas de la sociedad y establecer canales de comunicación y relación que permitan estrechar vías de colaboración conjunta y, sobre todo, generar la necesaria sintonía entre lo que unos y otros están en disposición de ofrecer y demandar.

Por último, y no por ello menos importante, están las organizaciones profesionales y científicas en las que se incorporan los profesionales y desde las que se regulan y modelan sus ofertas y se desarrollan las lineas científico-profesionales que les dan consistencia y valor; pero que, lamentablemente, también actúan de manera endogámica y alejadas de la realidad social a la que se deben. El necesario e imprescindible asociacionismo se torna en un feroz corporativismo que, en muchas ocasiones, tan solo se preocupa por salvaguardar los intereses particulares de sus miembros.

Y este complejo entramado social, sanitario, universitario y científico-profesional configura escenarios inciertos en los que las enfermeras desempeñan un papel fundamental. Los cambios demográficos, epidemiológicos, sociales, políticos y económicos están generando una demanda social de cuidados enfermeros cada vez mayor; pero, al mismo tiempo, esta demanda se exige cada vez más cercana y participativa, lo que obliga a las enfermeras a adaptar sus competencias con el fin de ser cada vez más eficaces y eficientes. Por su parte, dichos cambios exigen nuevas estructuras sociosanitarias que se alejen del hospitalcentrismo y la atención biologicista y medicalizada, y en las que la técnica debe dejar paso a una personalización de los cuidados enfermeros integrales, integrados e integradores, y se acerquen a los lugares donde las personas trabajan, se relacionan, estudian y viven, y se centren en la atención domiciliaria, en la cual la intervención familiar debe ser un objetivo fundamental y un 
permanente compromiso de las enfermeras. Y, a la vez, teniendo claro el necesario empoderamiento de la sociedad en la toma de decisiones.

Las facultades/escuelas de enfermería, por su parte, deben ser sensibles a todo este proceso y trabajar activamente con la sociedad para lograr formar profesionales capaces y capacitados, y para desarrollar investigaciones para la comunidad, por ella y con ella, que generen evidencias con las cuales sustentar la práctica enfermera de calidad científica pero, o sobre todo, humana, que limite la variabilidad y que permita que las enfermeras sepan qué hacer, que quieran hacerlo y sepan cómo hacerlo, al tiempo que no existan condicionantes externos "insalvables" que lo "impidan" (sociales, organizativos, etc.).

Las sociedades científicas y los colegios profesionales deben actuar como el necesario eslabón de cohesión, fortaleza y avance que de consistencia científico-profesional a todo el proceso. Alejándose de las batallas estériles que las distraigan del verdadero objetivo: ofrecer los mejores cuidados a personas, familias y comunidades.

Los actores de cada uno de estos contextos deben actuar en perfecta armonía y sincronización entre ellos y entre los ciudadanos si quieren, realmente, lograr reconocimiento social, valor profesional, calidad académica, alto nivel científico, imagen y desarrollo. No hacerlo supondrá perpetuar la invisibilidad enfermera, restar valor a los cuidados y generar respuestas fallidas a las demandas que se trasladan.

La enfermería comunitaria y las enfermeras comunitarias (de salud colectiva o familiares, según los diferentes países) son las que más y mejor preparadas están para dar respuesta a todas estas exigencias desde una perspectiva amplia, global, integrada, integradora y racional para la sociedad y para las instituciones. De ellas depende que la sociedad sea capaz de identificarlas, valorarlas y demandarlas como tales y de los responsables políticos tener la valentía y el acierto de apostar por ellas, como vienen recomendando los principales organismos internacionales de salud. 
